\title{
TENDÊNCIAS À MERCANTILIZAÇÃO E PRIVATIZAÇÃO DA UNIVERSIDADE E DO ENSINO SUPERIOR DIANTE DA ATUAL CONJUNTURA POLÍTICO-ECONÔMICA NO BRASIL
}

\author{
Trends to mercantilization and privatization of the University and \\ Higher Education before the current political-economic setting in Brazil
}

\begin{abstract}
Tendencias a la mercantilización y privatización de la Universidad y de la Enseñanza Superior ante la actual conjuntura política-economica en Brasil
\end{abstract}

\begin{abstract}
RESUMO $O$ artigo objetiva discutir quais as tendências desenhadas atualmente para a Educação Superior e para a universidade pública no Brasil, considerando as discussões acerca dos processos de privatização e mercantilização que, historicamente, incidem sobre esse setor. Metodologicamente, realizou-se uma revisão da literatura a respeito da temática, contrastando-a com algumas contrarreformas empreendidas ou intencionadas pela presente gestão do executivo federal. É possível dizer que há forte tendência ao aprofundamento da mercantilização e privatização do segmento, derivados dos cortes orçamentários e sucateamento de instituições públicas, do acirramento da competitividade nas universidades, do prejuízo da formação crítica; e, no ensino superior, do fortalecimento da oligopolização do setor.
\end{abstract}

Palavras-chave: Ensino Superior. Mercantilização. PrivatizaÇÃO. UNIVERSIDADE. CIÊNCIA E TECNOLOGIA.

ABStRACT The article aims to discuss the current trends in Higher Education and the public university in Brazil, considering the discussions about the privatization and commercialization processes that have historically focused on this sector. Methodologically, a review of the literature on the subject was carried out, contrasting it with some counter-reforms undertaken or intended by the current management of the federal executive. It is possible to say that there is a strong tendency to deepen the commodification and privatization of the segment, derived from the budget cuts and scrapping of public institutions, the increase of competitiveness in the universities, the damage of the critical formation; and, in higher education, the strengthening of oligopolization of the sector.

Keywords: Higher Education. Commodification. Privatization. University. Science and Technology.

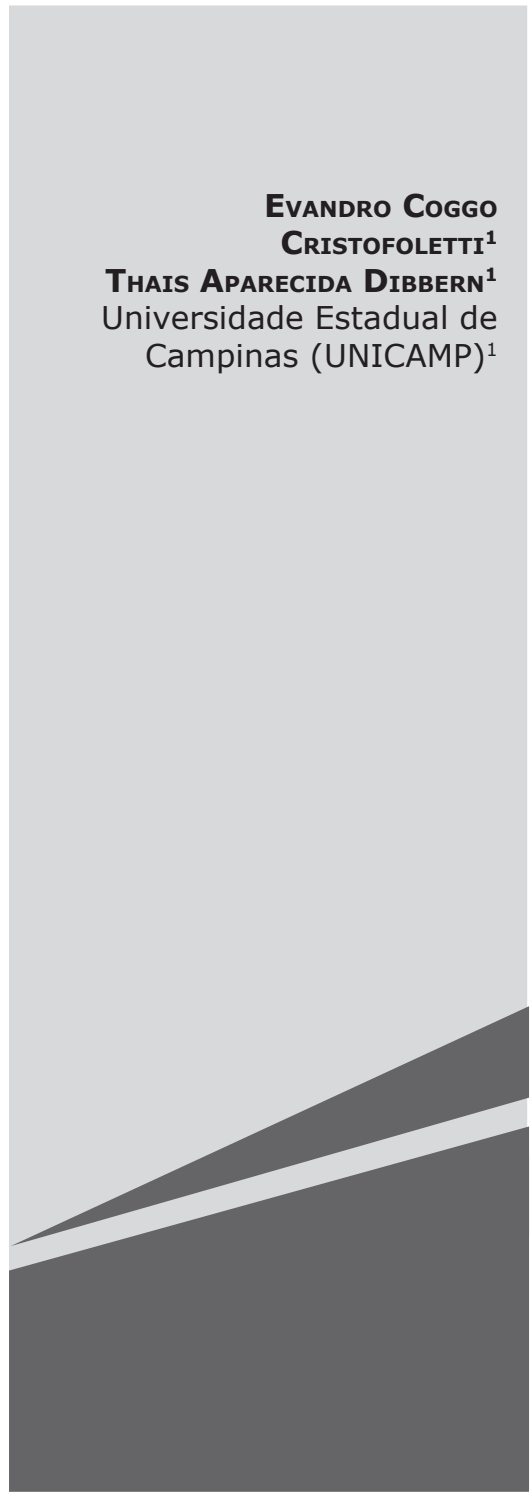




\begin{abstract}
RESUMEN El artículo objetiva discutir cuáles son las tendencias diseñadas actualmente a la Educación Superior y a la universidad pública en Brasil, considerando las discusiones acerca de los procesos de privatización y mercantilización que, históricamente, inciden sobre este sector. Metodológicamente, se realizó una revisión de la literatura sobre la temática, contrastándola con algunas contrarreformas emprendidas o intencionadas por la actual gestión del ejecutivo federal. Es posible decir que hay una fuerte tendencia a la profundización de la mercantilización y privatización del segmento, derivados de los recortes presupuestarios y de la sucursal de instituciones públicas, del acrecimiento de la competitividad en las universidades, del perjuicio de la formación crítica; y en la enseñanza superior, del fortalecimiento de la oligopolización del sector.
\end{abstract}

Palavras clave: Enseñanza Superior. Mercantilización. PRIVATIZACIÓN. UniVERSIDAD. CienCIA Y TECNOloGía.

\section{INTRODUÇÃO}

O artigo objetiva debater, de forma exploratória, o panorama e as tendências atuais da educação superior e da universidade pública no Brasil, levando-se em conta algumas medidas adotadas pelo governo federal nos últimos dois anos. Em outras palavras, procuraremos, de forma exploratória, identificar como a discussão acerca da mercantilização e privatização desse nível de ensino está sendo "atualizada" pelas várias contrarreformas liberais implementadas ou intencionadas. $\mathrm{O}$ artigo tem caráter exploratório, visto que as questões levantadas, atuais e em constante movimento e complexidade, suscitam debates diversos. Por isso, a análise feita neste artigo tem uma abordagem mais panorâmica.

Metodologicamente, operou-se a pesquisa em duas etapas, que representam a divisão tópica do artigo: primeiramente, consideraram-se alguns debates, levando-se em conta a bibliografia acadêmica, sobre mercantilização e privatização do ensino superior e da universidade, na tentativa de explicar, de maneira geral, o fenômeno e suas formas de manifestação no Brasil. Na segunda etapa, recorremos a uma análise dos estudos acadêmicos recentes que abordam questões relacionadas à condição do ensino superior nos últimos três anos. Consultaram-se diretamente as fontes e leis oficiais governamentais, bem como, documentos (notícias e relatórios) relevantes aos temas aqui abordados - como o documento "Ponte para o Futuro" lançado, em 2015, pelo partido Movimento Democrático Brasileiro (PMDB) e o relatório do Banco Mundial chamado "Um Ajuste Justo: Análise da eficiência e equidade do gasto público no Brasil" (2017); para além das diversas medidas governamentais que afetaram a educação superior.

\section{A MerCantilizaÇão e PRIVATIZaÇão dA Universidade E do Ensino Superior}

Denominamos de mercantilização da universidade pública e privatização do ensino superior os processos de intensificação da racionalidade mercantil no seio das universidades públicas e nas políticas que as afetam, bem como, o crescimento e oligopolização das faculdades privadas do tipo lucrativas (MARTINS, 2008; LEHER, 2004; ROSA, 2016; MARQUES, 2013; SGUISSARDI, 2015; MINTO, 2014; DIAS; SERAFIM, 2015; SOUZA, 2010). Dessa forma, aumenta-se o grau de intensidade da aproximação, por parte das universidades públicas, com os interesses e demandas do setor produtivo, seja no âmbito da forma- 
ção, da pesquisa e da extensão. Somam-se a isso as tentativas de modificação administrativa e pedagógica pautados em princípios e métodos provindos da gestão empresarial, como a racionalização de recursos com vistas à eficiência "econômico-administrativa", bem como, a modificação dos currículos dos cursos de graduação e pós-graduação para adequação dos interesses do mercado. Nesse meio, problemas como precarização do trabaIho docente, terceirização, flexibilização, bem como, o sucateamento estrutural das IES públicas se fazem presentes.

No plano do ensino superior como um todo, observamos, historicamente, processos de fragmentação e diversificação institucional das IES, com fins à especialização organizacional, para a venda de serviços de educação direcionados a públicos-alvo e segmentos específicos, acompanhando de perto as necessidades laborais do mercado; em segundo lugar, observou-se a expansão das IES particulares com fins lucrativos em movimentos, já evidentes, de oligopolização do setor, atuando em um "nicho" de mercado ainda bastante rentável e destinado à valorização das ações das empresas do ramo (MANCEBO, 2017; MARQUES, 2013; DIAS SOBRINHO, 2013; 2014; GORGEN, 2014).

De forma geral, pode-se dizer que a mercantilização e a privatização do ensino superior no Brasil ganharam forma e força a partir dos governos militares. Contudo, esses processos se intensificam a partir da emergência do neoliberalismo e da mundialização do capital, ocorridos no mundo a partir da década de 1970, e que no Brasil se fizeram sentir, principalmente, na década de 1990. Acompanham esse processo as mudanças no mundo do trabalho, com relativo enfraquecimento do paradigma fordista e fortalecimento de "modelos" produtivos mais flexíveis, bem como, maior desregulação e crescimento do capital financeiro; emergência das tecnologias da informação e comunicação; e o crescimento da terceirização, das desigualdades, do desemprego, instabilidade social e política, entre outros problemas. Essas mudanças afetaram a educação superior em boa parte do mundo. A diversificação institucional nos sistemas de ensino superior e o crescimento do setor privado também são resultados desse contexto, manifestando-se sob diferentes formas em diversos países (MANCEBO, 2017).

Voltando ao Brasil, a partir da década de 1990, o projeto hegemônico pontuava que:

1) que era preciso redefinir a função do governo (Estado) com relação ao ensino superior, reduzindo sua participação enquanto organizador e financiador, e, consequentemente, aumentando sua dimensão avaliadora do ensino e das IES. Em paralelo, começava a se ampliar a discussão, no âmbito da OMC, sobre a colocação da educação superior no setor de serviços negociados mundialmente, também denominada de "comodificação" (Cf. LEHER, 2010, p. 42-3); 2) fomentar a diversificação das IES e a diferenciação das modalidades de ensino, desestimulando o "modelo único" e criando condições de acesso mais variadas, para públicos também variados; 3 ) incentivar as IES públicas a diversificarem suas fontes de financiamento por meio de parcerias (sobretudo com o setor privado) (... 4) vincular o financiamento público às IES públicas a uma política de resultados, relacionadas com metas de eficiência, de eficácia, sendo estas entendidas como um novo sentido para a qualidade e para as práticas de avaliação. No caso do financiamento à pesquisa científica e tecnológica, ter a "inovação" como centro dinâmico dessa cobrança de resultados; (... 5) favorecer e estimular, no conjunto da educação superior, o funcionamento do mercado como ente regulador, devendo assim conceder mais autonomia às IES, desburocratizando os proces- 
sos de abertura, credenciamento e funcionamento das IES (... 6) promover "alternativas" de ensino mais baratas para fazer frente ao problema da escassez de recursos e do baixo índice de acesso da população jovem ao nível superior, como os cursos de curta duração e o ensino a distância (MINTO, 2014, p. 239-240).

É claro que esses processos não ocorreram sem resistências e refluxos, tanto por parte de docentes, estudantes e funcionários - organizados ou não - quanto por parte de movimentos sociais em geral no sentido da defesa da educação pública, como o Fórum Nacional em Defesa da Escola Pública. A própria Constituição de 1988 garantiu a gratuidade de ensino nos estabelecimentos públicos, bem como, ratificou a indissociabilidade entre ensino, pesquisa e extensão. No campo da Educação Superior, por exemplo, tivemos a atuação em defesa da universidade pública do Sindicato Nacional dos Docentes das Instituições de Ensino Superior (ANDES). Discussões como autonomia didático-científica e administrativa, democratização da universidade e compromisso social são temas ainda recorrentes nas disputas no campo educacional. Nesse sentido, as políticas de educação estão permeadas por disputas de hegemonia: razão pela qual estamos falando em processos de intensificação de mercantilização e privatização, e não de fenômenos acabados e plenamente estabelecidos.

Essas disputas se expressam, de forma diferente, ao longo dos anos de 1990 e dos primeiros quinze anos do século XXI. Diversas políticas foram implementadas neste segmento: como a Lei de Diretrizes Base da Educação (LDB); os Planos Nacionais de Educação; a instituição do Conselho Nacional da Educação; o Financiamento Estudantil (FIES) e o Programa Universidade Para Todos (PROUNI); as reformas no sistema nacional de avaliação do ensino superior; as políticas de ações afirmativas; o Programa de Expansão das Universidades
Federais (Reuni); a edição da Lei de Inovação (Lei n. 10.973, de 02/12/2004)e, recentemente, o Marco Legal da Ciência e Tecnologia e Inovação (Lei n. 13.243, de 11/01/16), que buscaram criar arranjos institucionais mais facilitadores à relação universidade-empresa.

Nesse sentido, a literatura consultada aponta, fundamentalmente, o conflito entre duas concepções de educação e de produção de conhecimento, aqui estilizadas: como um direito público voltado à cidadania, democracia e pensamento crítico versus educação privatizada, segmentada, voltada ao lucro e fortemente orientada às necessidades do mercado. No âmbito institucional, no interior das universidades públicas, esse conflito se expressa sob a noção do compromisso social: discute-se em que medida o ensino e a produção de conhecimento deveriam centrar-se nas demandas mercadológicas pautadas por um mundo laboral mais instável e flexível, onde o conhecimento se torna cada vez mais um fator produtivo essencial ao crescimento econômico e à competitividade de empresas e nações por meio de inovações tecnológicas - a chamada "economia do conhecimento" (DIAS SOBRINHO, 2013; GOERGEN, 2014); ou se o ensino, a ciência e a extensão deveriam preparar indivíduos e produzir conhecimento, ainda que aptos a exercer suas funções produtivas, para atuar crítica e reflexivamente diante de problemas sociais diversos e variados que atingem nossa sociedade, sobretudo para com segmentos e classes sociais marginalizados e explorados (DIAS SOBRINHO, 2015; DAGNINO, 2015).

Para ilustrar o debate, segundo o último Censo da Educação Superior (INEP, 2018), cujos dados se referem a 2015, "observa-se o predomínio inequívoco das IES privadas (2.069), as quais são seguidas pelas IES estaduais (120), federais (107) e municipais (68)" (p. 12). No total, o país conta com 2.364 instituições de ensino superior (somando-se faculdades, universidades, centros universitários, institutos federais e centros de educação tecnológica), com as IES privadas, sejam elas com ou sem fins lucrativos, representando $87,5 \%$ do total. 
Bom ressaltar que $83,8 \%$ dessas instituições se encontram na categoria administrativa "faculdade". Em 2015, as IES privadas anotaram $6.075 .152(75,7 \%)$ matrículas e as IES públicas, 1.952.145 (24,3\%). Historicamente, observamos um explosivo crescimento nas matrículas em relação ao início da década de 1990, tanto nas IES públicas quanto privadas. Em 1990, tivemos 1.540 .080 matrículas presenciais, sendo $62,4 \%$ em IES privadas (CORBUCCI; KOBOTA; MEIRA, 2016). Segundo os autores, em 2000, registraram-se 2.694.245 matrículas, com $67,1 \%$ em instituições privadas. Já em 2010, tivemos o número de 5.449 .120 , com $73,2 \%$ das matrículas em IES privada.

Convém destacar que a evolução das IES privadas se deu por dois fatores (CORBUCCI; KOBOTA; MEIRA, 2016): as inversões de recursos públicos por meio do Fies e Prouni; e, não somente por conta dessas políticas, por uma nova fase de reestruturação das IES privadas, marcada pelos processos de fusão, aquisição e abertura acionária. Pode-se especificar (p. 14-15):

No campo da educação superior, aquisições e fusões ganham corpo a partir de meados da primeira década dos anos 2000. A feição empresarial do setor é fortalecida, a partir desse momento, por novas formas de negociação, entendidas aqui como compra, venda e fusão empresariais, investimentos do tipo private equity (...) O corolário desse novo ambiente econômico são as grandes corporações, as megafusões e a ampliação da participação do capital estrangeiro na educação nacional (...) O primeiro grande ciclo de fusões e aquisições no Brasil vai de 2005 a 2010, por meio da compra de IES e cursos de línguas estrangeiras. A partir de 2010, observa-se que, para além desses tipos de instituições de ensino, outros ramos e setores afins também passam a ser negociados, tais como editoras, gráficas, esco- las de ensino fundamental e médio e cursos pré-vestibulares. $\mathrm{O}$ que se observa, nesses casos, é a busca pela diversificação dos negócios, mediante a ampliação do portfólio de produtos e serviços ofertados por esses grandes grupos empresariais (...) Assim, entre os anos 2007 e 2015, foram realizadas 208 transações financeiras do tipo aquisições, vendas e fusões entre as principais empresas de educação em solo nacional (KPMG, 2016, p. 22), sendo que, desse total, 139 transações foram atribuídas às instituições de educação superior até o ano de 2014 (CM Consultoria, 2014, p. 1). Entre 2007 e 2014, cerca de 56 operações financeiras de expressivo porte foram realizadas por quatro dos maiores grupos educacionais do país.

Por conta disso, se debate a questão da tendência à oligopolização da educação superior, com nítido movimento de concentração de capital (MARQUES, 2013). Bom ressaltar que a crítica aqui exposta incide, principalmente, naquelas instituições privadas cujo objetivo principal é ofertar cursos e diplomas rápidos, de qualidade questionável, alinhados estritamente a demandas do mercado, em busca de melhores retornos em relação aos investimentos realizados (MARTINS, 2008).

\section{As tendênCias atuais à EducaÇão SUPERIOR}

Começamos este item com a ressalva de que, para debater as tendências à educação superior e à universidade pública, faz-se necessário ter em mente a própria conjuntura política atual -, por exemplo, discutir as causas do impedimento sofrido, em 2016, pela então presidente Dilma Rousseff -, bem como, nossa condição estrutural de dependência, que parece estar se aprofundando. Todavia, o objetivo e o escopo do artigo não nos permitem aprofundar esse debate. 
De forma geral, para Löwy (2016, p. 52), no Brasil, tivemos "um golpe pseudolegal, supostamente dentro do Estado de direito, mas com uma restrição cada vez maior dos direitos". Para o autor, a democracia, no mundo, acabou se tornando um peso muito grande ao grande capital e suas frações (sobretudo a financeira), prejudicando a continuidade do projeto neoliberal. O Brasil não fugiu desse contexto, apesar de possuir suas especificidades. Para Löwy (2016) e Leher et al. (2017), mediante um panorama de crise econômica e política no Brasil, ocorreu a quebra do "pacto" que havia permitido um governo de esquerda, mesmo que tímido, governar. Sobretudo nos últimos três anos, buscou-se recrudescer a estratégia do ajuste macroeconômico, sob o pretexto do combate à inflação e da retomada do crescimento, aprofundando e fortalecendo as agendas liberais e conservadoras nos planos econômico, político, social e educacional (MANCEBO, 2017; MELO; SOUZA, 2017; LEHER et al., 2017; LOWY, 2016). Em suma, transferimos esta longa citação enquanto resumidora da conjuntura que se desenha:

A força relativa do "lulismo" - lastreada pela memória de que, afinal, em seus governos, ocorreram melhorias nas condições de vida de grande massa da população, em virtude do ciclo ascendente do PIB e do consumo de massa - está desvinculada, em grande parte, do PT e da CUT. Existe uma expressão material que fundamenta a perda de apoio do governo Dilma que não decorre apenas das corporações da mídia: uma severa crise econômica e social que já é mais longeva do que a terrível crise de 1982. O diagnóstico elaborado pela Casa das Garças para suposta saída da crise é simplório: a crise é fiscal. É preciso cortar fundo os gastos sociais para proteger o pagamento do serviço e dos juros da dívida assumida pelo Estado e, não me- nos importante, em associação com a contrarreforma da previdência e a flexibilização da legislação trabalhista (sobrepondo o acordado sobre o legislado). Somente um governo não eleito, mas com forte apoio do Congresso poderia dar conta dessa tarefa: retirar os ganhos sociais da Constituição de 1988. De fato, com a PEC 55 o governo pretende colocar um fim na vinculação dos benefícios da seguridade ao valor do salário-mínimo, nas verbas constitucionalmente asseguradas para educação e saúde, gratuidade do ensino nos estabelecimentos oficiais, regime jurídico único para os servidores, aposentadorias do regime geral e dos regimes próprios da previdência, universalidade do Sistema Único de Saúde, preservação de áreas indígenas, função social da terra (...) Tais medidas aprofundarão a condição capitalista dependente, notadamente a exploração e a expropriação dos trabalhadores, o saqueio dos recursos naturais, a simplificação das cadeias [produtivas] (LEHER; VITTORIA; MOTTA, 2017, p. 17-18).

A educação superior encontra-se dentro desse contexto e suas tendências são determinadas por esse movimento geral, apesar das particularidades do setor. Assim, cabe dizer, de antemão, que há intensificação da mercantilização e da privatização não só do ensino superior e da universidade pública, mas também de outros serviços públicos, setores econômicos e até mesmo da sociabilidade em geral. $O$ interessante a se notar é como isso vem ocorrendo considerando a temática proposta.

De acordo com Melo e Souza (2017), após o impedimento ocorrido em meados de 2016, ocorreu uma desarticulação político-administrativa no campo da política da educação, sobretudo em secretarias e equipes do MEC, acarretando prejuízo à participação social no setor: houve recusa no "recebimen- 
to para audiências dos setores historicamente posicionados em defesa da educação pública; destituição e esvaziamento do Conselho $\mathrm{Na}$ cional da Educação e, praticamente, a destruição do Fórum Nacional da Educação" (p. 27). Somam-se a isso os cortes orçamentários aplicados a algumas ações ministeriais pontuais.

Para explicar essas ações - e outras que comentaremos a seguir - achamos pertinente citar dois documentos exemplares a se discutir as tendências à educação superior no Brasil. O primeiro deles foi lançado em outubro de 2015 pelo partido do Movimento Democrático Brasileiro (PMDB), chamado de "Uma Ponte Para o Futuro".

Neste, desenhou-se a linha estratégica de atuação do governo pós-impedimento. Não faremos uma análise desse documento. Porém, pode-se dizer que o grande mote trazido à tona no texto é o de que o Estado gastaria muito com políticas públicas, sendo necessário retomar o “equilíbrio fiscal”, apostando em uma estratégia de desenvolvimento centrada na iniciativa privada por meio do avanço das privatizações e terceirizações, bem como, diminuição do custo do trabalho e no aumento de sua produtividade (PMDB, 2015). Retomando Mancebo (2017), o documento propõe: um regime orçamentário com desvinculação de receita, acarretando no fim do modelo de financiamento da educação e da saúde pública; o fim da política de valorização do salário mínimo; a desregulamentação e flexibilização das leis trabalhistas para amenizar o "custo" do trabalho para o empresário; reforma da previdência; o aumento de privatizações, "em que se pode esperar o fim do regime de partilha e o controle da Petrobras, do Pré-Sal e a venda de ativos da Caixa Econômica e do Banco do Brasil" (p. 880); entre outras.

A temática da educação não foi muito abordada, ficando em segundo plano. Porém, o panorama que se desenhou foi claro: os gastos públicos em educação, em todos os níveis, haveriam de ser diminuídos. Não podemos afirmar qual o grau de sucesso efetivo pelo qual a estratégia desenhada naquele documento logrou nos dois anos seguintes. Con- tudo, pode-se se dizer que parte dos projetos avançou em passos largos por intermédio de medidas governamentais e projetos de leis.

Por exemplo, editou-se a Proposta de Emenda à Constituição nº. 55, de 2016, chamada de PEC do Teto dos Gastos Públicos (PEC 241/2016, conhecida popularmente como “PEC do Fim do Mundo"). ${ }^{1}$ Grosso modo, a emenda prevê o congelamento, por 20 anos, dos gastos públicos em diversas áreas:

De acordo com a Conof (Consultoria de Orçamento e Fiscalização Financeira) da própria Câmara dos Deputados, com a aprovação da PEC 241/2016 (PL 55) devem deixar de ser investidos anualmente nada menos que $\mathrm{R} \$ 24$ bilhões na educação. Isso corresponde à diferença entre o mínimo de $18 \%$ que a constituição estabelece como obrigatório para União investir e os gastos previstos para 2017 acrescidos da inflação do ano anterior. Somando-se as perdas acumuladas nos próximos 20 anos, a educação terá um prejuízo de aproximadamente 480 bilhões de reais. Só no final de março de 2017, com o chamado "ajuste fiscal”, de uma só vez, o governo Temer cortou R\$ 9,4 bilhões da educação (...) Segundo o próprio governo, ou seja, não é nenhum crítico dos golpistas que está falando, quando comparado com 2016, em 2017, as universidades devem sofrer corte de até $45 \%$ dos recursos previstos para investimentos e $18 \%$ para custeio. De acordo com cálculos de reitores das universidades federais, quando comparados com os $\mathrm{R} \$ 900$ milhões previstos para o setor em 2016, teremos um corte de aproximadamente $\mathrm{R} \$ 350$ milhões só em

Segundo fonte oficial, a PEC foi aprovada em plenário e está para promulgação do gabinete. Disponível em: <https://www25.senado.leg.br/web/atividade/ materias/-/materia/127337>. 
investimentos nas 63 federais (VIEIRA, 2016) (ORSO, 2017, p. 60).

Nesse sentido, o processo de mercantilização se intensifica, concretamente, via corte de recursos às IES públicas federais. Na prática, isso significa sucateamento estrutural, pois as obriga a realizar o mesmo - ou mais - trabalho com menos recursos.

Com efeito, quase todos os autores consultados apontam a PEC enquanto um dos principais determinantes da tendência da educação superior no Brasil (MANCEBO, 2017; LEHER et al. 2017; FIGUEIREDO, 2017; ORSO, 2017; MINTO, 2017; MELO; SOUZA, 2017). Segundo Leher et al. (2017), essa contenção orçamentária representará queda anual nos gastos sociais da ordem de $0,8 \%$ do PIB por ano, equivalendo, em seis anos, a toda verba destinada à educação brasileira atualmente (em torno de $5 \%$ do PIB). Em termos qualitativos, outros efeitos do congelamento, para as universidades, são trazidos por Minto (2017, p. 10):

...o contingenciamento financeiro promovido pela PEC 55 também implicará maior disputa por recursos públicos, diretos e indiretos, para a ciência e tecnologia entre os setores público e privado (...) O trabaIho docente, enfim, estará bastante sensível a tudo isso: a PEC 55 não só torna a prática do arrocho salarial uma imposição estatal (por até 20 anos!), como prevê sanções - como a suspensão de concursos públicos - que poderão, de um lado, impor maior intensificação do trabalho dos docentes ativos; por outro lado, abrir espaço para a precarização das contratações docentes, por meio de expedientes como terceirizações, contratos temporários, professores horistas, etc. Some-se a isso a possibilidade de retrocessos nos regimes previdenciários das instituições estatais, o que poderia estimular nova onda de aposenta- dorias antecipadas nas IES públicas. Vê-se, assim, que desgastes físico e psíquico ampliados, maior competitividade e relações predatórias nas universidades públicas...

Dessa forma, a tendência é de que o trabalho intelectual (docência, pesquisa e extensão) fique mais comprometido, com aumento da precarização do trabalho docente nas universidades públicas, bem como, intensificação da competição interna por recursos provindos de agências de fomento e de organizações públicas e privadas (MANCEBO, 2017). Claro que algumas áreas do conhecimento pouco afetas à lógica do mercado, mas com grande importância social e científica, poderão desvalorizar-se. Pontuamos também que a precarização também atinge os professores das faculdades privadas, com diminuição salarial e mais instabilidade (inclusive pela reforma trabalhista empreendida).

Nessa linha, o segundo documento que gostaríamos de destacar como exemplar às tendências atuais à educação superior é o relatório do Banco Mundial, lançado em 2017, chamado de "Um Ajuste Justo: Análise da eficiência e equidade do gasto público no Brasil". O documento possui um capítulo destinado à educação e, dentro deste, um item referente ao ensino superior. No documento, revisou-se a "qualidade e eficiência" do gasto público brasileiro nas últimas duas décadas. De forma geral, as conclusões do relatório não fogem ao que já foi apontado: desenha-se a necessidade de se controlar o gasto estatal, pois o governo brasileiro, nos últimos vinte anos, gastou muito e mal, colocando em xeque a sustentabilidade fiscal do Estado (BANCO MUNDIAL, 2017). Nesse sentido, a redução do gasto público e as políticas de ajuste fiscal superavitário seriam imperativos ao equilíbrio macroeconômico e à retomada do crescimento. Na temática aqui abordada, recomendou-se que:

Os gastos públicos com o ensino superior também são altamente 
ineficientes, e quase $50 \%$ dos recursos poderiam ser economizados. Os gastos públicos com ensino fundamental e médio são progressivos, mas os gastos com o ensino superior são altamente regressivos. Isso indica a necessidade de introduzir o pagamento de mensalidades em universidades públicas para as famílias mais ricas e de direcionar melhor o acesso ao financiamento estudantil para o ensino superior (programa FIES) (BANCO MUNDIAL, 2017, p. 121).

Convém clarificar que esses apontamentos não são algo novo: nas décadas de 1980 e 1990, essa mesma entidade já alertava aos países latino-americanos a necessidade de se diversificar institucionalmente esse segmento de ensino, flexibilizando-o, estimulando o ensino privado, baixando seu "custo social e público” (MARTINS, 2008; MINTO, 2014).

A análise do Banco Mundial tem viés econômico e argumenta que o gasto público, no geral, com educação do Brasil ultrapassa seus "pares internacionais" (BRICS). Assim, desenha-se o argumento de que o custo do estudante em universidades públicas chega a três vezes mais do que um aluno de faculdade privada, tida por isso como mais eficiente. Além disso, o relatório conclui que o gasto público em IES públicas tende a beneficiar a parcela mais rica da população, que tem maior acesso a essas instituições. Nesse sentido, o documento recorre a uma estratégia argumentativa que se apoia na desigualdade educacional histórica brasileira (derivada justamente das outras desigualdades estruturais) e no suposto "custo" eficiência da rede privada para justificar a cobrança de mensalidades na rede pública superior, a flexibilização, terceirização e implantação de mecanismos de gestão mais "eficientes" nas IES públicas, além de estimular o crescimento da rede privada. As recomendações não deixam margem de dúvida:
Limitar os gastos por aluno aos níveis das universidades mais eficientes geraria uma economia imediata de $0,26 \%$ do PIB. As universidades que receberem menos recursos como resultado desta medida teriam de reconsiderar sua estrutura de custos e/ou buscar recursos em outras fontes, como já é a norma nos sistemas acadêmicos com os melhores níveis de desempenho; Uma opção para aumentar os recursos das universidades federais sem sobrecarregar o orçamento seria a introdução de tarifas escolares (...) Paralelamente, é necessário facilitar o acesso a mecanismos de financiamento para estudantes que não possam pagar as mensalidades. Felizmente, o Brasil já possui o programa FIES, que oferece empréstimos estudantis para viabilizar o acesso a universidades privadas (p. 138).

Que fique claro que não estamos discutindo a influência direta desse documento nas políticas e medidas governamentais. O que é fato, porém, é que sua edição veio a calhar com o momento histórico em que se vive.

Diversas críticas podem ser feitas. De maneira geral, a principal delas relaciona-se com a metodologia empregada: utiliza-se de uma abordagem econométrica que desconsidera, qualitativamente, a história das universidades e instituições públicas de ensino superior no país (AMARAL, 2018). Omite-se a importância de se considerar a pesquisa científica e a extensão enquanto funções realizadas, quase exclusivamente, por universidades públicas coisa que não entrou nos cálculos do relatório (universidades particulares também realizam pesquisa e extensão, sobretudo as sem fins lucrativos). Além disso, a utilização do argumento de que as universidades são elitizadas para justificar a cobrança de mensalidades mascara a verdadeira fonte deste fenômeno: a própria situação histórica de desigualdade econômica 
e social da sociedade brasileira, cujas políticas neoliberais defendidas pelo relatório contribuem ao seu aumento. ${ }^{2}$ Aumentaria, assim, a massificação do ensino superior, em prejuízo à democratização.

Até aqui, vimos que a literatura consultada aponta, fundamentalmente, que o ajuste fiscal e as medidas de austeridades implementadas pelo atual governo, com o intuito de transferir os efeitos de uma crise econômica e política nacional e internacional para os mais pobres, estão impactando diretamente a educação pública básica e superior ao reduzir seu orçamento. Isso geraria impactos qualitativos no trabalho docente (MANCEBO, 2017; PEIXOTO, 2016; LEHER et al., 2017; FIGUEIREDO, 2017). Nessa linha, na opinião de Mancebo (2017) e Minto (2017), a orientação da política educacional do atual governo se insere nas estratégias de adaptação de um país periférico e dependente à crise mundial do capital deflagrada em 2008. Nesse sentido:

...o movimento da expansão de matrículas e cursos - como foi o caso do REUNI - é refreado em função dos ajustes, deixando às instituições a amarga tarefa de reconfigurar diversos procedimentos internos, para fazer frente à expansão (do período anterior) que lhes legou mais alunos, cursos, campi e forte interiorização, sem o devido financiamento. A estratégia mais imediatamente observada é a dos cortes de verbas de manutenção e renovação das instituições, abandonando a infraestrutura física dos campi. Todavia, as dificuldades não se esgotam aí. Outro movimento de acomodação à atual conjuntura, já perceptível em algumas IES públicas, refere-se a certo enxugamento de suas funções, priorizando o

Amaral (2008) conclui, em análise detalhada da metodologia e dos cálculos do Banco Mundial, que há diversas imprecisões e distorções quantitativas e qualitativas no estudo. ensino, em detrimento das demais (MANCEBO, 2017, p. 884).

Daí que a resposta tendencial das IES públicas seria flexibilizar e "otimizar" suas atividades, acarretando modificações administrativas e gerenciais importantes. Assim, se destaca a tendência, nas IES públicas, a recorrer às estratégias de terceirização, que se antes já eram feitas em alguma medida nas atividades auxiliares, seriam implementadas cada vez mais às atividades fins (ensino, pesquisa e extensão).

$\mathrm{Na}$ análise de Leher et al. (2017), a conjuntura econômica e política atual estaria se assemelhando à da ditadura militar no Brasil, pesando-se as diferenças conjunturais e estruturais, sobretudo no que se refere ao padrão de exploração do trabalho e da acumulação do capital, bem como, reforço do neoconservadorismo político. A educação teria que se adequar a esse processo. Como exemplo, os autores citam a reforma do Ensino Médio (Medida Provisória $\left.\mathrm{n}^{\circ} .746 / 16\right)$ e as propostas afetas ao movimento "Escola Sem Partido". Na prática, as medidas buscariam reduzir a pressão por matrículas nas universidades públicas, com o intuito de formar recursos humanos para trabalhos simples, "para colocar o exército industrial de reserva apto para pressionar os salários para baixo" (p. 19). Além disso, para os autores, a formação pretendida por essa reforma "obstaculiza a secularização e a laicidade da vida social, manipulando os jovens com valores conservadores que pretendem difundir o medo diante das incertezas e da complexidade do século XXI". Tem-se o prejuízo, assim, de uma formação crítica e voltada aos problemas sociais. Corroborando com a análise, Melo e Souza (2017, p. 31) pontuaram que algumas medidas efetivadas nas políticas educacionais objetivam alinhar o ensino de graduação à "necessidade de aumento da produtividade do trabalho, via formação profissional dirigida para o trabalho flexível, especialmente pelo aumento da escolaridade voltado para as necessidades da integração dos mercados do capitalismo internacional”. 
Outra tendência que pode ser destacada no ensino superior brasileiro, com Mancebo (2017), Minto (2017) e Figueiredo (2017), é a de que a crise econômica e política vem sendo lucrativa aos grandes empresários da educação superior. Como vimos no item anterior, o setor privado-mercantil observou crescimento substancial nos últimos 20 anos. Com efeito, há tendência ao fortalecimento do movimento de oligopolização, com a facilitação dos processos de fusões e aquisições, bem como fortalecimento dos grupos internacionais atuantes nesse "nicho" de negócios. Ao mesmo tempo em que há diversificação das modalidades, há concentração de capital. Por conseguinte, se reforça a influência política desses setores no Estado (legislativo e executivo).

Para Leher et al. (2017) e Minto (2017), o projeto à educação superior que se coloca atualmente contribuiria para uma adequação mais "eficiente" do Brasil dentro da divisão internacional do trabalho. Nesse sentido, os autores pontuam que as medidas já destacadas também afetam centralmente a pesquisa científica brasileira, que em grande medida é realizada nas universidades públicas: "percebia-se que, mesmo precário em muitos aspectos, o aparato científico e tecnológico construído no decorrer do século XX (...) tornava-se agora 'excessivo', 'caro', 'ineficiente' ao projeto dominante” (MINTO, 2017, p. 5). Na visão do relatório da Andes (2018), o baixo investimento em C\&T (seja estatal ou empresarial) "expressa a natureza do capitalismo dependente brasileiro, cuja competitividade se baseia historicamente na superexploração da força de trabalho e na produção intensiva/ extensiva de produtos primários com baixo ou nenhum valor agregado" (p. 92).

Nessa linha, pode-se apontar, com Martins (2017), no âmbito das reestruturações ministeriais promovidas por Michel Temer, a redução em uma só pasta, sem fundamento administrativo, dos Ministérios da Ciência, Tecnologia e Inovação e o das Comunicações. Além disso, se verificaria cortes para C\&T:
Os cortes e contingenciamentos se fizeram de maneira ainda mais dura na política de C\&T, onde, em valores atuais, o governo central reduziu as despesas a pouco menos da metade do dispêndio de 2010, algo em torno de 5,5 bilhões de reais até o momento em que fechamos este caderno (segundo informado no Portal da Transparência). O Ministério de Ciência, Tecnologia, Inovação e Comunicações gastou, até o presente momento, 6,6 bilhões de reais, algo em torno da metade do orçamento executado pelo órgão em 2010. Desventura idêntica sofreu o CNPq: as despesas do órgão acumuladas em 2017 somam, até o momento (dezembro), nada mais que 1,2 bilhões de reais, representando em torno de $50 \%$ dos 2,5 bilhões executados em 2013. Com a CAPES o tratamento do governo central não tem sido diferente, pois, nesse órgão, o acumulado de despesas dentro do ano de 2017 alcançou, até agora, 2,8 bilhões de reais em contraste com os 5,2 bilhões de reais despendidos pelo governo central em 2016 (a preços de janeiro de 2017) (ANDES, 2018, p. 16)

Dessa forma, compromete-se a pesquisa, atingindo direta e indiretamente os bolsistas de pós-graduação e os demais pesquisadores, com reflexo, novamente, na competição por recursos e na reorganização acadêmica e administrativa das IES.

Com este tópico, buscamos panoramizar alguns aspectos relativos às tendências que se desenham ao ensino superior como um todo. Outras medidas governamentais também poderiam ser comentadas, como a própria reforma trabalhista e os impactos nas atividades de docência, sobretudo nas faculdades e universidades privadas, questão que não aprofundamos aqui. 


\section{CONSIDERAÇões FINAIS}

Ao longo do artigo, procuramos mostrar que, historicamente, nosso ensino superior e nossas universidades públicas são afetadas pelos processos de mercantilização e privatização que, a depender da conjuntura, se manifestam sob diferentes formas. Esse movimento acompanha a própria estruturação do projeto neoliberal no país ao longo da última década do século XX e dos primeiros dezoito anos do século XXI.

Sobretudo nos últimos três anos, a partir do impedimento de Dilma Rousseff, em 2016, esses processos vêm avançando em taxas rápidas, expressas por cortes orçamentários, que sucateiam as instituições públicas, comprometimento da pesquisa científica, acirramento da competição interna, precarização do trabalho docente; privilegiamento cada vez maior de pesquisas que consigam captar recursos externos, incluindo-se a possibilidade de cobranças de mensalidades em instituições públicas; a adoção de mecanismos de terceirização e flexibilização administrativa e das próprias atividades-fim nas IES; prejuízo da formação crítica em geral; aumento de transferências de recursos públicos às IES privadas; entre outras. Além destas, se aprofundará a privatização do ensino superior, com reforço do movimento de oligopolização e concentração de capital.

É claro que os rumos da história não são fechados, e as tendências debatidas podem não se concretizar a depender da atuação política que venha oferecer resistências a esses processos.

\section{REFERÊNCIAS}

ANDES. Neoliberalismo e Política de C\&T no Brasil Um balanço crítico (1995-2016). Cadernos Andes, Brasília, n. 28, p. 1-144, 2018.

CORBUCCI, P. R.; KUBOTA, L. C.; MEIRA, A. P. B. Reconfiguração estrutural da educação superior privada no Brasil: nova fase da mercantilização do ensino. Texto Para Discussão Ipea, $n$. 2.256, p. 1-42, 2016.

DAGNINO, R. Como é a universidade de que o Brasil precisa? Avaliação, v. 20, n. 2, p. 293-333, 2015.

DAGNINO, R. Por que nossos empresários não inovam? Revista Economia e Tecnologia, v. 13, p. 111-120, abr./jun. 2008.

DIAS SOBRINHO, J. Educação superior: bem público, equidade e democratização. Avaliação, Sorocaba, v. 18, n. 1, p. 107-126, 2013.

DIAS SOBRINHO, J. Universidade e novos modos de produção, circulação e aplicação do conhecimento. Avaliação, Sorocaba, v. 19, n. 3, p. 643-662, 2014.

DIAS, R.; SERAFIM, M. P. Comentários sobre as transformações recentes na universidade pública brasileira. Avaliação, Sorocaba, v. 20, n. 2, 2015.

DOURADO, L. F. Reforma do Estado e as políticas para a educação superior no Brasil nos anos 90. Educação \& Sociedade, v. 23, n. 80, p. 235-253, 2002.

FIGUEIREDO, J. C. Impeachment no Brasil: O governo Temer e a privatização nas universidades públicas brasileiras. Germinal: Marxismo e Educação em Debate, v. 9, n. 3, p. 161-181, 2017. 
GOERGEN, P. Tecnociência, pensamento e Formação na educação superior. Avaliação, Sorocaba, v. 19, n. 3, p. 561-584, 2014.

GRUPO BANCO MUNDIAL. Um Ajuste Justo: Análise da eficiência e equidade do gasto público no Brasil. 2018. Disponível em: <http://documents.worldbank.org/curated/pt/884871511196609355/ pdf/121480-REVISED-PORTUGUESE-Brazil-Public-Expenditure-Review-Overview-Portuguese-Final-revised.pdf>. Acesso em: 28 mai. 2018.

INEP. Censo da Educação Superior 2003: resumo técnico. Brasília: Ministério da Educação, 2003. INEP. Resumo técnico: censo da Educação Superior 2015. Brasília: Ministério da Educação, 2018. LEHER, R. Para silenciar os campi. Educação \& Sociedade, v. 25, n. 88, p. 867-891, 2004.

LEHER, R.; VITTÓRIA, P.; MOTTA, V. C. Educação e mercantilização em meio à tormenta político-econômica do Brasil. Germinal: Marxismo e Educação em Debate, v. 9, n. 1, p. 14-24, 2017.

LOWY, M. Da tragédia à farsa: o golpe de 2016 no Brasil. In: Por que gritamos golpe? Para entender o impeachment e a crise política no Brasil. In: JINKINGS, I. et al. Por que gritamos golpe? Para entender o impeachment e a crise política no Brasil. São Paulo: Boitempo, 2016.

MANCEBO, D. Crise Político-Econômica no Brasil: Breve análise da educação superior. Educação \& Sociedade, v. 38, n. 141, p. 875-892, 2017.

MANCEBO, D.; VALE, A. A.; MARTINS, T. B. Políticas de expansão da educação superior no Brasil 1995-2010. Revista brasileira de educação, v. 20, n. 60, 2015.

MARQUES, W. Expansão e oligopolização da educação superior no Brasil. Avaliação, Sorocaba, v. 18, n. 1, p. 69-83, 2013.

MARTINS, A. L. M. A Marcha do "Capitalismo Universitário" no Brasil nos anos 1990. Avaliação, Sorocaba, v. 13, n. 3, p. 733-743, 2008.

MARTINS, M. F. Ciência e educação em risco de sobrevivência no Brasil. Crítica Educativa, v. 3, n. 1, p. 1-4, 2017.

MELO, A. A. S.; SOUSA, F. B. A Agenda do Mercado e a Educação no Governo Temer. Germinal: Marxismo e Educação em Debate, v. 9, n. 1, p. 25-36, 2017.

MINTO, L. W. A educação da miséria: particularidade capitalista e educação superior. São Paulo: Outras Palavras, 2014, 400p.

MINTO, L. W. Impactos das recentes medidas governamentais sobre a educação superior e o trabalho docente. Anais do Encontro Internacional e Nacional de Política Social, v. 1, n. 1, 2017.

ORSO, P. J. A Educação em Tempos de Golpe, ou então, como avançar andando para trás. Germinal: Marxismo e Educação em Debate, v. 9, n. 1, p. 50-71, 2017. 
PEIXOTO, E. M. Conjuntura, Luta de Classes e Educação. Germinal: Marxismo e Educação em Debate, v. 8, n. 1, p. 1-19, 2016.

PMDB. Uma ponte para o futuro. São Paulo: Fundação Ulysses Guimarães, 2015. Disponível em: <https://www.fundacaoulysses.org.br/wp-content/uploads/2016/11/UMA-PONTE-PARA-O-FUTURO.pdf >. Acesso em: 27 mai. 2018.

ROCHA, S. Educação de qualidade e democrática: um direito de todos - desafios da educação básica. In: FONSECA, A.; FAGNANI, E. (Orgs.). Políticas sociais, desenvolvimento e cidadania, v. 2. São Paulo: Editora Fundação Perseu Abramo, 2013.

ROSA, F. N. A docência na educação superior brasileira: bem público ou educação-mercadoria? Revista Brasileira de Ensino Superior, v. 2, n. 3, p. 58-66, 2016.

SGUISSARDI, V. Educação Superior no Brasil: democratização ou massificação mercantil. Educação \& Sociedade, v. 36, n. 133, p. 867-889, 2015.

SOUZA, A. L. L. A História da Extensão Universitária. Campinas: Editora Alínea, 2010.

VALENTE, I.; ROMANO, R. PNE: Plano Nacional de Educação ou carta de intenção? Educação \& Sociedade, v. 23, n. 80, 2002.

\section{EvANDRO COGGO CRISTOFOLETTI}

Doutorando em Política Científica e Tecnológica pela Universidade Estadual de Campinas (UNI(AMP).evandro.coggo@gmail.com

\section{ThaIS APARECIDA DIBBERN}

Doutoranda em Política Científica e Tecnológica pela Universidade Estadual de Campinas (UNI(AMP).dibbern.thais@gmail.com

Submetido em: 18-6-2018

Aceito em: 14-1-2019 